\title{
OS CONHECIMENTOS QUE EMERGEM DA RÉGUA DE CARPINTEIRO DE LEONARD DIGGES (1520-1559) A PARTIR DA VISÃO DOS LICENCIANDOS EM MATEMÁTICA DA UECE
}

\author{
THE MATHEMATICAL CONCEPTS EMERGING FROM LEONARD DIGGES'S \\ CARPENTER'S RULER (1520-1559) FROM THE VIEW OF UECE MATHEMATICS \\ LICENSORS
}

\author{
Sabrina de Sousa Paulino ${ }^{1}$; Ana Carolina Costa Pereira ${ }^{2}$
}

\begin{abstract}
RESUMO
Como forma de contribuir para o processo de construção de uma aliança entre a história da matemática e o ensino, muitos pesquisadores brasileiros têm realizado estudos a respeito das potencialidades didáticas no processo de inserção de instrumentos matemáticos ao ensino. A partir de um tratamento didático, tais instrumentos podem ser aplicados a um determinado grupo acadêmico, como forma de legitimar esses artefatos como um recurso ao professor de Matemática. Dessa forma, o intuito desse artigo é apresentar as percepções dos participantes do minicurso "A matemática no processo de graduação da régua de carpinteiro de Leonard Digges (1520 - 1559)", realizado na XXV Semana Universitária da Universidade Estadual do Ceará, em relação aos conceitos matemáticos incorporados ao instrumento régua de carpinteiro. Assim, para que esse objetivo fosse alcançado, se fez necessário, realizar um estudo descritivo, no qual foram expostos e registrados alguns dados obtidos a partir das discussões e atividades realizadas no minicurso. A partir da coleta e descrição dos dados obtidos na realização do minicurso, foi possível observar que os participantes identificaram, no instrumento régua de carpinteiro, itens potencialmente didáticos, associados aos processos de construção e graduação da régua. Conteúdos presentes atualmente na educação básica foram identificados pelos cursistas, como a divisão, multiplicação, frações equivalentes etc. Portanto, é possível concluir que a régua de carpinteiro e a tabela de medidas da madeira, possuem itens potencialmente didáticos, que podem contribuir com $o$ processo de construção de uma interface entre a história da matemática e o ensino, com o foco principalmente voltado para a incorporação de instrumentos matemáticos ao ensino.

Palavras-chave: Régua de Carpinteiro; Instrumentos Matemáticos; Ensino de Matemática.
\end{abstract}

\begin{abstract}
As a way of contributing to the process of building an alliance between the history of mathematics and teaching, many Brazilian researchers have carried out studies on the pedagogical potential in the process of inserting mathematical instruments into teaching. From a didactic treatment, such

${ }^{1}$ Graduanda no curso de Licenciatura Plena em Matemática da Universidade Estadual do Ceará (UECE). Bolsista de Iniciação Científica (CNPq/UECE), Fortaleza, Ceará, Brasil. E-mail: sabrina.paulino@aluno.uece.br.

(iD) ORCID iD: https://orcid.org/0000-0002-8309-8757.

${ }^{2}$ Pós-Doutora em Educação Matemática pela Pontifícia Universidade Católica de São Paulo (PUC-SP). Docente do programa de Pós-Graduação em Educação e do curso de Licenciatura em Matemática da Universidade Estadual do Ceará (UECE), Fortaleza, Ceará, Brasil. Endereço para correspondência: Av. Silas Munguba, 1700, Itaperi, Fortaleza, Ceará, Brasil, CEP: 60.740-903. E-mail: carolina.pereira@ uece.br.

(i) ORCID iD: http://orcid.org/0000-0002-3819-2381.
\end{abstract}


instruments can be applied to a certain academic group, as a way to legitimize these artifacts as a resource to the mathematics teacher. Thus, the purpose of this article is to present the perceptions of participants in the mini-course "Mathematics in the process of graduating from the carpenter's ruler by Leonard Digges (1520 - 1559)", held at the XXV University Week of the State University of Ceará, in relation to mathematical concepts incorporated into the carpenter's ruler instrument. Thus, in order for this objective to be achieved, it was necessary to conduct a participant research supported by a descriptive study, in which some data obtained from the discussions and activities carried out in the mini-course were described and recorded. Supported by this, it was also necessary to carry out a bibliographic study on scientific articles whose focus is turned to the construction of an interface between history and the teaching of mathematics. From the collection and description of the data obtained during the mini-course, it was possible to observe that the participants identified, in the carpenter's ruler instrument, potentially didactic items, associated with the construction and graduation processes of the ruler. Currently present contents in basic education were identified by course participants, such as division, multiplication, equivalent fractions, etc. Therefore, it is possible to conclude that the carpenter's ruler and the wood measurement table have potentially didactic items, which can contribute to the process of building an interface between history and the teaching of mathematics, with a focus mainly on incorporation of mathematical tools into teaching.

Keywords: Carpenters Ruler; Mathematical Instruments; Mathematics Teaching. 


\title{
Introdução
}

Recentes investigações na área de história da matemática têm voltado seus focos para o estudo das possíveis potencialidades didáticas presentes no processo de incorporação de documentos originais ${ }^{3}$ ao ensino de matemática, como forma de construir uma interface entre a história da matemática e o ensino. Segundo Pereira e Saito (2019, p. 5),

\begin{abstract}
A escolha do documento tem em vista a realização de dois movimentos: um que busca contextualizar historicamente os conhecimentos matemáticos nele descritos e outro, revelando o movimento do pensamento na formação do conceito matemático que se quer abordar, seja para ensiná-lo, seja para compreendê-lo, no seu processo de construção para o sujeito.
\end{abstract}

Nesse sentido, Saito (2015), ainda ressalta que tais documentos, não são necessariamente apenas textos escritos, mas, monumentos, máquinas, fotos etc. A partir disso, a utilização desses artefatos históricos vem sendo considerada uma grande ferramenta no processo de construção de uma aliança entre a história da matemática e o ensino.

Assim, nas últimas décadas, tais artefatos históricos têm recebido cada vez mais atenção por parte de pesquisadores da educação matemática, em especial para esse estudo, destacam-se os instrumentos matemáticos ${ }^{4}$ de modo que, tem-se realizado diversos estudos a respeito dos conhecimentos matemáticos e extra matemáticos incorporados a eles (PEREIRA; BATISTA; SILVA, 2017; CASTILLO, 2016; ARGEMIRO FILHO; PAULINO; PEREIRA, 2020; PEREIRA; SAITO, 2018).

A esse respeito, Saito (2019, p. 4), explica que

[...] um exame minucioso sobre o contexto de sua elaboração tem revelado interessantes aspectos do "saber-fazer" matemático de uma época e contribuído para preencher algumas lacunas do processo da construção do conhecimento matemático nas origens da ciência moderna. Restituídos à malha histórica, os instrumentos matemáticos e os seus respectivos tratados, juntamente com outros documentos dedicados à geometria prática, introduzem novas questões para o historiador da ciência e da matemática.

Dessa forma, para esse estudo, tomou-se como documento histórico primário o tratado A Booke Named Tectonicon, escrito e publicado pela primeira vez no ano de

\footnotetext{
3 Segundo Silva (2018, p.40), tais documentos podem ser "[...] os materiais provenientes de uma determinada sociedade do passado como "documentos originais", que podem ser utilizados para promover a construção do conhecimento na articulação entre história da matemática e ensino".

${ }^{4}$ Para mais informações, vide Saito (2015).
} 
$1556^{5}$, de autoria do inglês praticante das matemáticas Leonard Digges (1520-1559). Tal documento aborda os conceitos matemáticos básicos para se realizar a atividade de agrimensor, tais como os caracteres numéricos, as frações e duas figuras, sendo elas o círculo e o triângulo.

Segundo Argemiro Filho, Paulino e Pereira (2020, p. 6), “[ [... o tratado proporciona ao artesão agrimensor, métodos de resolver problemas de ordem prática presentes em seu cotidiano". Nesse sentido, Tectonicon não só registrava conhecimentos matemáticos de ordem prática, mas também tinha por objetivo, repassar tais instruções para facilitar o ofício do artesão agrimensor no século XVI.

Além disso, o tratado também expõe os processos de construção, graduação e aplicação de três instrumentos matemáticos, sendo eles o báculo (crosss-staffe), a régua de carpinteiro (carpenters ruler) e o esquadro de carpinteiro (carpenters squire). Dentre os três instrumentos apresentados por Digges (1605), destaca-se para esse estudo o instrumento régua de carpinteiro, que foi o enfoque de um minicurso ofertado na XXV Semana Universitária da Universidade Estadual do Ceará.

Com isso, esse texto tem o intuito de apresentar as percepções dos participantes do minicurso intitulado "A matemática no processo de graduação da régua de carpinteiro de Leonard Digges (1520 - 1559)", em relação aos conceitos matemáticos incorporados a construção do instrumento régua de carpinteiro.

\section{Metodologia}

No que se refere ao caminho metodológico percorrido, pode-se dividir esse estudo em duas etapas, na qual, a primeira, se deteve estritamente a aplicação do minicurso e a segunda, em realizar uma análise dos dados obtidos no minicurso, a partir da percepção dos próprios participantes.

Nessa perspectiva, a aplicação do minicurso seguiu uma metodologia de pesquisaparticipante, que segundo Prodanov e Freitas (2013), ocorre quando pesquisador e participantes, a partir de uma interação e discussões, desenvolvem conhecimentos a respeito de um determinado tema. Dessa forma, o minicurso foi uma ferramenta, que

\footnotetext{
${ }^{5}$ Vale ressaltar que para esse estudo foi tomado como documento primário a versão do tratado publicada no ano de 1605.
} 
possibilitou a obtenção de dados, que podem, após uma análise, ser utilizados para embasar o estudo maior que está sendo realizado.

Nesse sentido, realizou-se o que Marconi e Lakatos (2003), definem como observação participante, que ocorre quando o pesquisador “[...] se incorpora ao grupo, confunde-se com ele. Fica tão próximo quanto um membro do grupo que está estudando e participa das atividades normais deste" (MARCONI; LAKATOS, 2003, p. 194).

Consequentemente, foi realizada uma análise dos dados obtidos no minicurso intitulado "A matemática no processo de graduação da régua de carpinteiro de Leonard Digges (1520 - 1559)". Tal etapa, seguiu uma metodologia descritiva, que segundo Prodanov e Freitas (2013, p. 52), é o ato em que se “[...] pesquisa, observa, registra, analisa e ordena dados, sem manipulá-los, isto é, sem interferência do pesquisador".

Tais dados, foram obtidos com o auxílio de algumas ferramentas, saber, 4 formulários do Google Forms ${ }^{6}$, contendo questionamentos a respeito dos conteúdos expostos. Também foram utilizados como recursos: imagens, 3 gravações de vídeo, os chats referentes as chamadas de vídeo realizadas durante os 3 dias de minicurso e depoimentos gerados a partir de momentos de discussões didáticas.

\section{Aspectos gerais do minicurso}

Com o intuito de compreender o processo de construção de uma interface entre a história da matemática e o ensino, foi elaborada uma proposta da realização de um minicurso para a XXV Semana Universitária da Universidade Estadual do Ceará, intitulado "A matemática no processo de graduação da régua de carpinteiro de Leonard Digges (1520 - 1559)", ocorrido no período dos dias 24 a 26 de novembro de 2020.

Esse minicurso contou com a presença de duas ministrantes e teve por objetivo apresentar os conceitos matemáticos presentes no processo de graduação da régua de carpinteiro de Leonard Digges (1520-1559), contida no tratado A Book Named Tectonicon (Figura 1).

\footnotetext{
${ }^{6}$ Aplicativo de gerenciamento de pesquisas e elaboração de formulários lançado pelo Google.
} 
Sabrina de Sousa Paulino e Ana Carolina Costa Pereira

Os conhecimentos que emergem da régua de carpinteiro de Leonard Digges (1520-1559) a partir da visão dos licenciandos em matemática da UECE

Figura 1 - A parte da frente da Régua de Carpinteiro

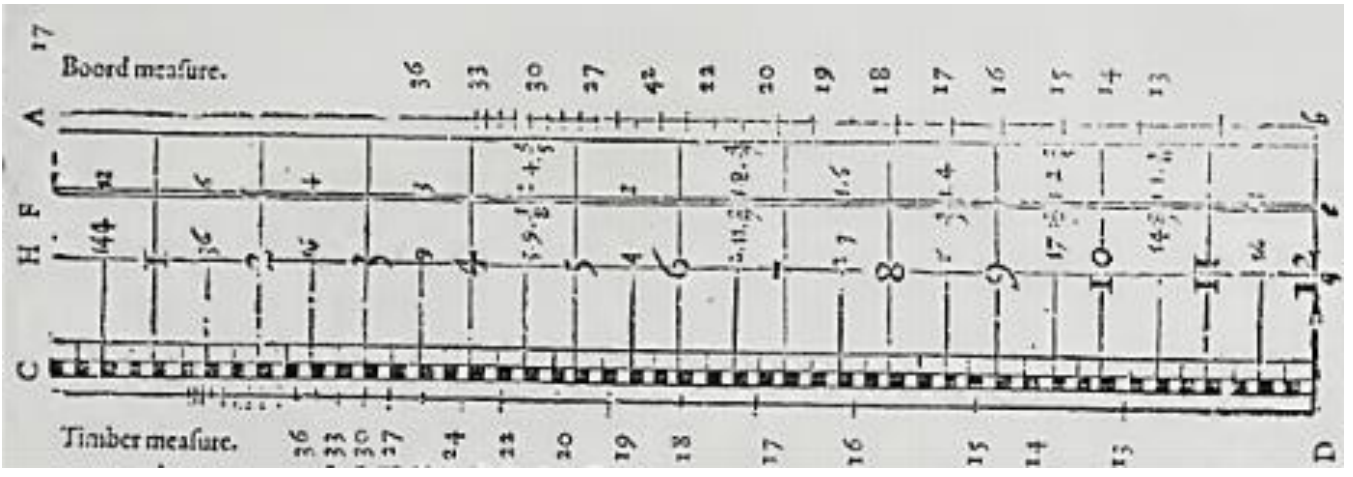

Fonte: Digges (1605, XII, p.1)

Com uma carga horária de 6 horas, o minicurso foi realizado à distância ${ }^{7}$, através do ambiente Google Meet $^{8}$, dispondo de 30 vagas, das quais todas foram preenchidas. No entanto, apenas 23 participaram de forma ativa do minicurso, preenchendo a frequência, respondendo aos formulários, interagindo as exposições de conteúdos e nas discussões pedagógicas.

É importante destacar que, tais vagas contemplaram não só alunos do curso de Licenciatura em Matemática, mas também de outros cursos, como Química, Física, Ciências Biológicas e participantes que já eram graduados (Gráfico 1).

Gráfico 1 - Os participantes ativos do minicurso

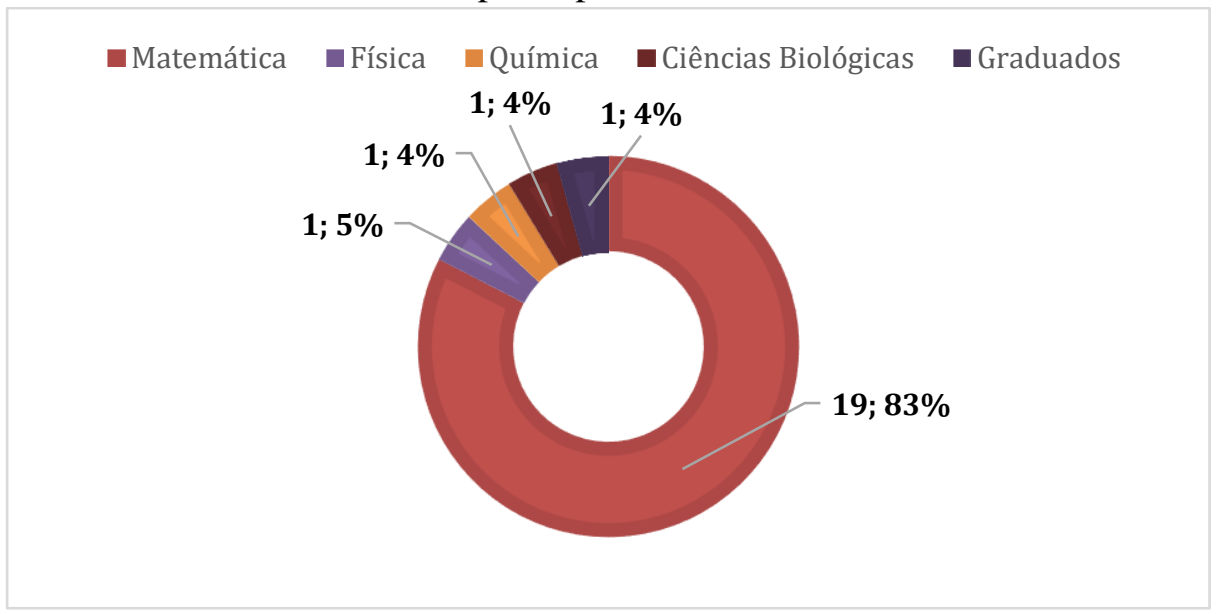

Fonte: Elaborado pelas autoras

\footnotetext{
${ }^{7}$ Em virtude da pandemia de Corona vírus, que teve seu início em 1 de dezembro de 2019.

${ }^{8}$ Aplicativo do Google que oferece serviços de chamadas de vídeo.
} 
Sabrina de Sousa Paulino e Ana Carolina Costa Pereira

Os conhecimentos que emergem da régua de carpinteiro de Leonard Digges (1520-1559) a partir da visão dos licenciandos em matemática da UECE

Dessa forma, para o desenvolvimento desse minicurso e uma melhor interação com os participantes, seguiu-se uma metodologia expositiva dialogada, que segundo Sá et al. (2017, p. 631) é

[...] uma estratégia em que o professor expõe o conteúdo, mas com participação ativa dos estudantes. Nesse tipo de aula, o professor leva os alunos a questionarem, interpretarem e discutirem o objeto de estudo a partir do reconhecimento e do confronto com a realidade.

Com isso, o professor assume um papel de mediador e os conhecimentos prévios dos estudantes são levados em consideração, tornando assim a exposição dos conteúdos um diálogo entre professor e aluno.

Nesse sentido, foram apresentadas aos participantes, as informações dispostas no tratado A Booke Named Tectonicon (1605) a respeito da construção da régua de carpinteiro $^{9}$ e da tabela de medidas da madeira ${ }^{10}$, como pode-se observar no Quadro 1 a seguir, com o objetivo fornecer as condições necessárias para que eles pudessem identificar os conceitos matemáticos associados ao processo de graduação de um instrumento matemático do século XVI, a régua de carpinteiro.

Quadro 1 - Conteúdo programático do minicurso

\begin{tabular}{|c|c|c|c|}
\hline Unidade Temática & Conteúdos da Unidade & $\begin{array}{c}\text { Atividades } \\
\text { Desenvolvidas }\end{array}$ & $\mathbf{C H}$ \\
\hline $\begin{array}{l}\text { UNIDADE 1: } \\
\text { Instrumento, obra e } \\
\text { autor. Uma introdução } \\
\text { sobre as matemáticas } \\
\text { do século XVI. }\end{array}$ & $\begin{array}{l}\text { - Apresentação do curso de } \\
\text { Extensão Universitária. } \\
\text { - A História da Matemática. } \\
\text { - A matemática do século XVI. } \\
\text { - Leonard Digges e sua obra A } \\
\text { Booke Named Tectonicon } \\
\text { (1556). }\end{array}$ & $\begin{array}{l}\text { - Encontro via Google } \\
\text { Meet. } \\
\text { - Questionário Inicial. } \\
\text { - Formulário de } \\
\text { questionamentos. } \\
\text { - Avaliação do dia. }\end{array}$ & $2 \mathrm{~h}$ \\
\hline $\begin{array}{l}\text { UNIDADE 2: A régua } \\
\text { de carpinteiro e a tabela } \\
\text { de medidas da madeira } \\
\text { de Leonard Digges. }\end{array}$ & $\begin{array}{l}\text { - O instrumento régua de } \\
\text { carpinteiro no tratado A } \\
\text { Booke Named Tectonicon } \\
\text { (1556). } \\
\text { - A tabela de medidas da } \\
\text { madeira de Leonard Digges. }\end{array}$ & $\begin{array}{l}\text { - Encontro via Google } \\
\text { Meet. } \\
\text { - Formulário de } \\
\text { questionamentos. } \\
\text { - Avaliação do dia. }\end{array}$ & $2 \mathrm{~h}$ \\
\hline $\begin{array}{l}\text { UNIDADE 3: A } \\
\text { graduação das escalas } \\
\text { da régua de carpinteiro, } \\
\text { a partir da tabela de } \\
\text { medidas da madeira }\end{array}$ & $\begin{array}{l}\text { - O processo de graduação das } \\
\text { escalas da régua de } \\
\text { carpinteiro. }\end{array}$ & $\begin{array}{l}\text { - Encontro via Google } \\
\text { Meet. } \\
\text { - Atividade } 1 . \\
\text { - Relatório de atividade. }\end{array}$ & $2 \mathrm{~h}$ \\
\hline
\end{tabular}

\footnotetext{
${ }^{9}$ Para mais informações a respeito da régua de carpinteiro, vide Paulino e Pereira (2021) e Argemiro Filho, Paulino e Pereira (2020).

${ }^{10}$ Para mais informações a respeito da tabela de medidas da madeira, vide Paulino e Pereira (2021).
} 


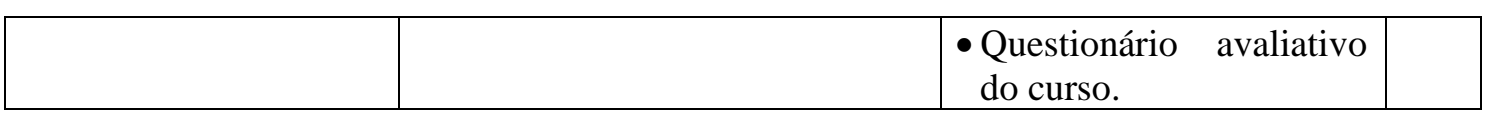

Fonte: Elaborado pelas autoras

É importante destacar que, como forma de legitimar tais dados, colhidos durante a realização do minicurso, foi firmado com os participantes, antes da realização do primeiro encontro, o Termo de Consentimento Livre e Esclarecido (TCLE), com prazo de preenchimento até as 22 horas do dia 24 de novembro de 2020. Esse documento, teve por objetivo obter a autorização dos participantes em se realizarem fotos e/ou vídeos, assim como a colher os depoimentos que ocorreram durante o andamento do minicurso. Além disso, esse curso está registrado no Conselho de Ética e Pesquisa (CEPE) da Universidade Estadual do Ceará (UECE), com o número de parecer 3.285.665.

Consequentemente, para que o objetivo do minicurso fosse alcançado, notou-se que seria necessário traçar um plano estrutural, dividindo-o em 3 unidades, no qual, cada uma possuiria conteúdos e objetivos específicos, como pode-se observar no Quadro 2 a seguir.

Quadro 2 - Planejamento do minicurso

\begin{tabular}{|c|c|c|c|}
\hline Objetivos & Unidade 1 & Unidade 2 & Unidade 3 \\
\hline $\begin{array}{c}\text { Para o } \\
\text { discente }\end{array}$ & $\begin{array}{l}\text { Reconhecer o tratado como } \\
\text { parte integrante do diálogo } \\
\text { entre as matemáticas e } \\
\text { compreender a importância } \\
\text { do autor para as } \\
\text { matemáticas do século } \\
\text { XVI. }\end{array}$ & $\begin{array}{l}\text { Conhecer a régua de } \\
\text { carpinteiro e a Tabela } \\
\text { de Medidas da } \\
\text { Madeira a partir das } \\
\text { descrições das suas } \\
\text { construções contidas } \\
\text { no tratado. }\end{array}$ & $\begin{array}{l}\text { Compreender o processo } \\
\text { de construção da régua } \\
\text { de carpinteiro e da tabela } \\
\text { de medidas da madeira. }\end{array}$ \\
\hline $\begin{array}{c}\text { Para o } \\
\text { docente }\end{array}$ & $\begin{array}{l}\text { Apresentar ao participante, } \\
\text { noções gerais sobre o } \\
\text { tratado, autor e o } \\
\text { instrumento que serão } \\
\text { estudados. }\end{array}$ & $\begin{array}{l}\text { Expor o processo de } \\
\text { construção, tal qual } \\
\text { está descrito pelo } \\
\text { autor. }\end{array}$ & $\begin{array}{l}\text { Estimular os } \\
\text { participantes a utilizarem } \\
\text { os conhecimentos que } \\
\text { foram identificados para } \\
\text { realizar o processo de } \\
\text { obtenção dos valores da } \\
\text { tabela de medidas da } \\
\text { madeira. }\end{array}$ \\
\hline
\end{tabular}

Fonte: Elaborado pelas autoras

No que se refere ao método avaliativo, é importante destacar que foram disponibilizados formulários com questionamentos e uma atividade, de forma que o participante teria que identificar os conceitos apresentados durante o minicurso, para que 
Sabrina de Sousa Paulino e Ana Carolina Costa Pereira

Os conhecimentos que emergem da régua de carpinteiro de Leonard Digges (1520-1559) a partir da visão dos licenciandos em matemática da UECE

assim, pudesse compreender e reproduzir o processo de graduação da régua de carpinteiro, a partir da tabela de medidas da madeira.

Além disso, também foi contabilizada a participação dos cursistas nas discussões didáticas acerca da temática estudada. Dessa forma, para obter o certificado do minicurso, o participante deve ter sido ativo nas atividades propostas, assim como nas discussões realizadas.

\section{Os conhecimentos mobilizados pelos participantes}

O minicurso foi dividido em três unidades, de forma que na primeira foi descrito o contexto social, político e econômico da Inglaterra, no século XVI e alguns aspectos a respeito da vida de Leonard Digges (1520-1559) e a sua importância para as matemáticas daquele período. Além disso, também foi apresentada a obra, à qual pertence o instrumento régua de carpinteiro, o tratado A Booke Named Tectonicon (1556) (Figura 2).

Figura 2 - Frontispício da obra A Booke Named Tectonicon (1605)



Fonte: Digges (1605)

Vale destacar, que para cada unidade, foi reservado um momento de discussão, no qual os próprios participantes, guiados pelas ministrantes do minicurso, comentaram, discutiram e indagaram a respeito das temáticas apresentadas.

Com isso, questionamentos foram levantados a respeito do contexto em que autor, obra e instrumento estavam inseridos, expondo informações sobre a época, o contexto e 
a civilização a qual eles pertenciam. Como consequência dessas discussões, um dos participantes, destacou que se deve

[...] entender que a matemática é resultado de uma construção histórica, do pensamento matemático e de como ele vai se desenvolvendo ao longo do tempo. O que a gente tem hoje em dia, é resultado de diversas transformações e aplicações da matemática, ao longo da história e ao longo dos tempos, nas diversas civilizações (PARTICIPANTE 9) ${ }^{11}$.

A partir disso, nota-se que o participante, interpretou o estudo contextual realizado, no qual, busca-se conhecer as influências externas que determinado conceito experienciou, como um fator de grande importância para se compreender o seu processo de elaboração.

Já a segunda unidade, teve o intuito de expor aos cursistas, informações a respeito do processo de construção física do instrumento régua de carpinteiro e sobre os valores expostos na tabela de medidas da madeira (Figura 3), a partir das instruções disponibilizadas pelo próprio autor.

Figura 3 - A tabela de medidas da madeira de Leonard Digges

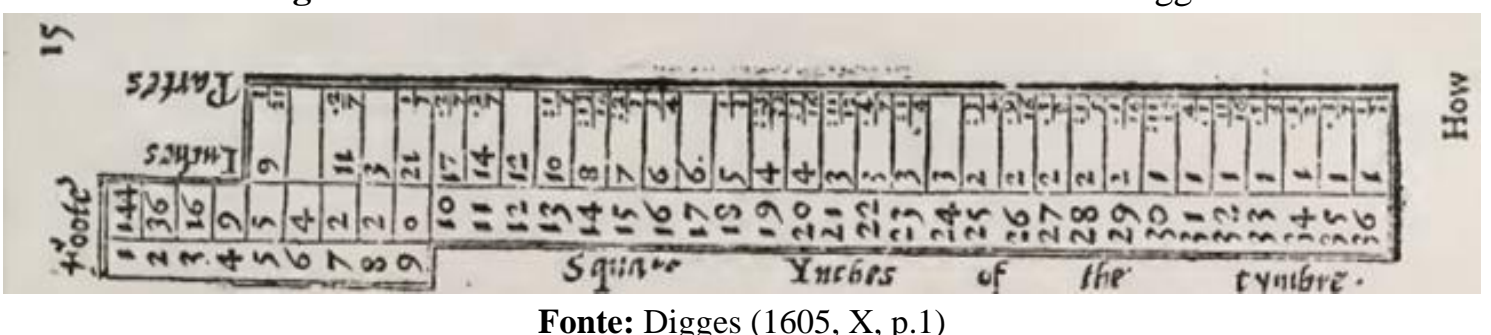

É importante destacar que o intuito dessa unidade não era de realizar a reconstrução do instrumento ${ }^{12}$, mas sim de apresentar os conhecimentos matemáticos que estavam sendo mobilizados na sua construção. Pereira e Saito (2019, p. 3), ainda ressaltam que "[...] um instrumento não é mero artefato, mas um suporte que veicula conhecimentos e, portanto, afigura-se como rico material que pode ser explorado com a finalidade de promover o ensino e a aprendizagem de matemática".

Nesse sentido, no que se refere as discussões realizadas a respeito da construção do instrumento, notou-se que os cursistas demonstraram um grande interesse a respeito

${ }^{11}$ Como forma de preservar a identidade dos participantes envolvidos no minicurso, eles serão representados pelos números 1 a 30 .

12 Para mais informações a respeito do processo de reconstrução de instrumentos matemáticos, vide Saito (2014) e Pereira e Saito (2019). 
da construção das escalas da régua de carpinteiro e sobre as unidades de medida relacionadas a elas. A partir disso, foi apresentado aos participantes um formulário avaliativo, no qual foram citados, pelos mesmos, alguns conceitos matemáticos percebidos no processo de construção da régua de carpinteiro.

O Gráfico 2, a seguir, dispõe os conteúdos que foram notados pelos cursistas e a quantidade de vezes em que tais conceitos foram citados, no formulário avaliativo disposto.

Gráfico 2 - Conteúdos observados pelos cursistas

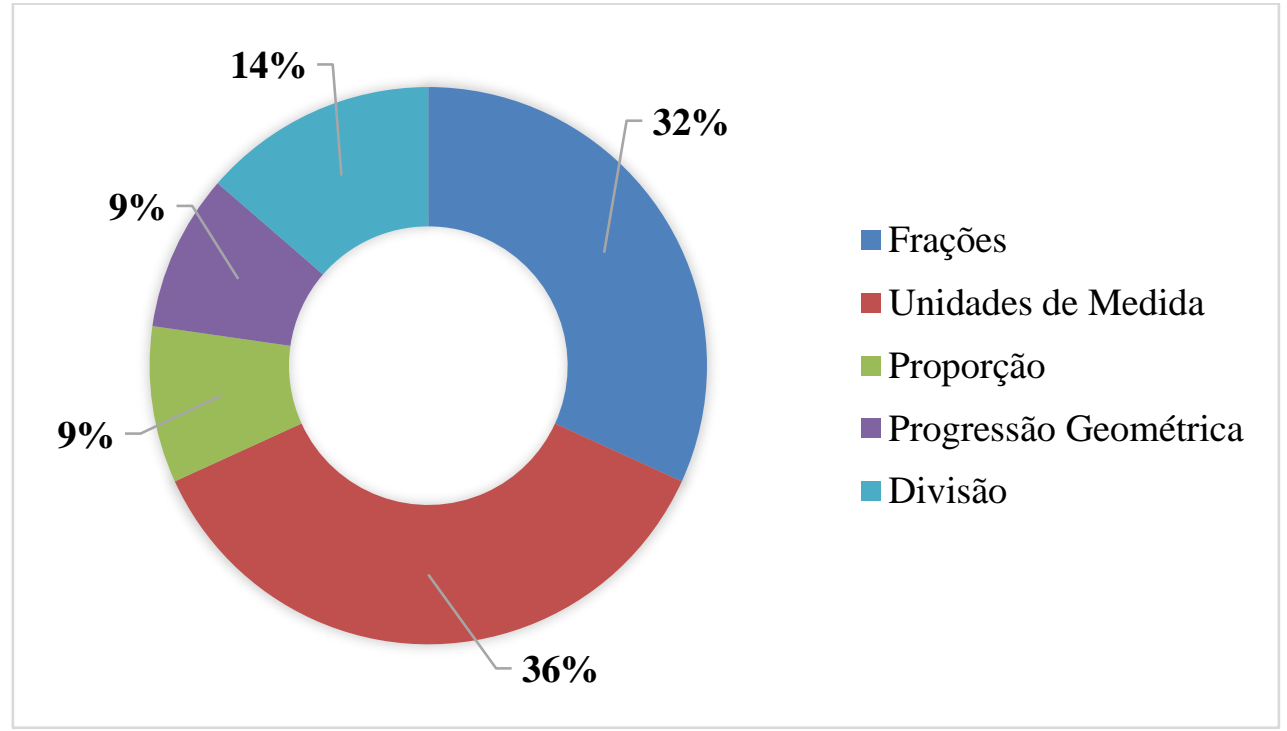

Fonte: Elaborado pelas autoras

A partir disso, é possível destacar que os cursistas perceberam, nas instruções apresentadas pelo autor a respeito da construção do instrumento, conceitos matemáticos que estão presentes até os dias de hoje na educação básica. Além disso, também é possível notar que dentre os conceitos observados, foi dado um maior destaque para os conhecimentos de unidades de medida e frações.

Ainda nas discussões realizadas na unidade 2, o Participante 19 observou que, a reconstrução e a incorporação da régua a sala de aula poderiam ser realizadas, "[...] de modo que possa ajudar a compreender um pouco mais sobre frações equivalentes”. Já o Participante 10, ressaltou que a reconstrução física do instrumento, mobilizam “[...] conceitos de fração, multiplicação e comparações".

As observações feitas pelos cursistas, referente ao conteúdo de frações, estão apontadas na Base Nacional Comum Curricular (BNCC), na unidade temática 
“Números”. Segundo Brasil (2018, p. 301), esse entendimento deve ser aplicado para se “(EF06MA07) Compreender, comparar e ordenar frações associadas às ideias de partes de inteiros e resultado de divisão, identificando frações equivalentes".

Dessa forma, notam-se indícios, fornecidos pelos comentários dos cursistas, de que a reconstrução e incorporação do instrumento régua de carpinteiro são importantes para a construção do conhecimento matemático, principalmente no que se refere a conceitos voltados para a educação básica, tais como operações com frações e multiplicação.

Os participantes, identificaram no processo de construção do instrumento, conceitos matemáticos que podem auxiliar os alunos a elaborarem um determinado conhecimento, tornando assim a régua de carpinteiro um recurso didático aos professores de Matemática.

Por fim, o terceiro módulo do minicurso, se deteve em apresentar aos participantes, o processo de graduação do instrumento régua de carpinteiro, a partir da obtenção dos valores da tabela de medidas da madeira, com o intuito de dispor ao cursista, todas as informações necessárias para que ele compreendesse o processo matemático realizado para graduar o instrumento.

Dessa forma, todos os dados a respeito desse processo de graduação, foram apresentados segundo as próprias instruções expostas pelo autor, no tratado. Nesse sentido, foram apresentados, aos cursistas, questionamentos a respeito da possível inserção da régua de carpinteiro e da tabela de medidas da madeira, em sala de aula, como recursos didáticos.

No que se refere ao processo de graduação desse instrumento, o Participante 10, observou que são mobilizados “[...] conteúdos comuns a sala de aula (divisão, multiplicação e etc.) além de ser uma forma interativa e lúdica de se aprender, o que torna o conteúdo extremamente divertido".

Consequentemente, a respeito da incorporação de instrumentos matemáticos a sala de aula, o Participante 25, observou que a régua de carpinteiro, pode ser inserida a sala de aula, de forma que "[...] com um tratamento didático certo para cada turma será uma incrível oportunidade para qualquer aluno assim como foi pra mim”.

Os conhecimentos destacados por ambos os participantes, são propostos na BNCC do ensino fundamental nos anos iniciais e finais, nas habilidades referentes ao objeto de 
conhecimento de representação fracionária dos números racionais. Brasil (2018, p. 295), destaca que tais conceitos devem ser mobilizados para

(EF05MA08) Resolver e elaborar problemas de multiplicação e divisão com números naturais e com números racionais cuja representação decimal é finita (com multiplicador natural e divisor natural e diferente de zero), utilizando estratégias diversas, como cálculo por estimativa, cálculo mental e algoritmos.

Dessa forma, pode-se destacar que os conceitos observados pelos cursistas, no processo de graduação do instrumento régua de carpinteiro e na obtenção dos valores da tabela de medidas da madeira, são tópicos presentes na educação básica, que podem ser apresentados aos estudantes a partir da incorporação, após um tratamento didático, da régua de carpinteiro a sala de aula.

Finalmente, ao final da terceira unidade, ainda foi disponibilizado, no formulário avaliativo, um questionamento aos cursistas, com o intuito de compreender como foi para eles a experiência de participar do minicurso. A esse respeito, o Participante 1, destacou que adorou

[...] participar, me diverti bastante e aprendi bastante, ver os conceitos e aplicar torna a experiência incrível, e é muito divertido pois o entendimento da régua e a construção da tabela lembram um mapa do tesouro, que seguindo um caminho escrito a anos e anos atrás nos leva ao objetivo.

Apoiado a isso, o Participante 27 ainda ressalta, no que se refere a experiência de participação no minicurso, que

Foi incrível, não pensava que seria tão dinâmico e empolgante aprender história da matemática, a dinâmica utilizada foi incrível, prendia a atenção do participante. Desde já agradeço a todos que proporcionaram essa pesquisa, vocês são maravilhosos!

Com isso, é possível notar que os participantes encontraram na realização do minicurso, momentos dinâmicos e divertidos, tornando assim o recurso a história da matemática, ou seja, a exposição dos assuntos relacionados ao contexto histórico, obra, autor e instrumento, uma experiência diferenciada e lúdica no processo de construção do conhecimento matemático. A respeito da mobilização desse recurso, os Parâmetros Curriculares Nacionais (PCN), destacam que

[...] pode oferecer uma importante contribuição ao processo de ensino e aprendizagem em Matemática. Ao revelar a Matemática como uma criação humana, ao mostrar necessidades e preocupações de diferentes culturas, em diferentes momentos históricos, ao estabelecer comparações entre os conceitos e processos matemáticos do passado e do presente [...] (BRASIL, 1998, p. 42). 
A partir disso, pode-se observar que, os cursistas identificaram no instrumento e no seu processo de graduação, itens potencialmente didáticos, que após um tratamento pedagógico, podem ser inseridos em sala de aula como forma de auxiliar e tornar o processo de construção de um determinado conhecimento matemático mais dinâmico.

\section{Considerações finais}

A partir dos comentários, realizados pelos cursistas, pode-se notar que foram identificados na régua de carpinteiro e nos seus processos de construção e graduação, conceitos matemáticos que estão presentes nos dias de hoje, na educação básica (divisão, multiplicação, frações, entre outros).

Assim, não só a régua de carpinteiro, mas também a tabela de medidas da madeira e o tratado histórico associado a elas, são um preâmbulo para que essa articulação entre a história e o ensino de matemática seja possível. Dessa forma, conclui-se, que a incorporação desses documentos à sala de aula, segundo os participantes, pode despertar nos discentes, interesses a respeito da elaboração de determinados conhecimentos matemáticos e das influências extra matemáticas associadas a eles.

No que se refere, a experiência dos alunos, pode-se concluir, a partir dos comentários feitos por eles, que o minicurso foi tido como um momento de aprendizado diversificado, que proporcionou aos cursistas a possibilidade de conhecer um pouco mais a respeito dessa interação entre a história da matemática e o ensino, e os auxiliou a realizar uma possível ressignificação dos conhecimentos incorporados ao instrumento e ao século XVI.

Nesse sentido, a incorporação do instrumento régua de carpinteiro ao ensino de matemática, constitui um caminho metodológico importante, no que se refere a possíveis formas de auxiliar os discentes a compreenderem certos conceitos matemáticos de forma diversificada e efetiva, buscando contribuir para a construção de uma aliança entre essas a história da matemática e o ensino.

\section{Agradecimentos}

Agradecemos a Universidade Estadual do Ceará (UECE) e ao Conselho Nacional de Desenvolvimento Científico e Tecnológico ( $\mathrm{CNPq}$ ), pelo apoio e fomento a essa pesquisa. 


\section{Referências}

BRASIL, Ministério da Educação. Base Nacional Comum Curricular do Ensino Médio. Brasília, 2018.

BRASIL, Parâmetros Curriculares Nacionais: terceiro e quarto ciclos: Matemática. Brasília: MECSEF, 1998.

CASTILLO, Ana Rebeca Miranda. Um estudo sobre os conhecimentos matemáticos incorporados e mobilizados na construção e no uso do báculo (cross-staff) em A Boke Named Tectonicon de Leonard Digges. 2016. 121 f. Tese (Doutorado) - Curso de Educação Matemática, Pontifícia Universidade Católica, São Paulo, 2016.

DIGGES, Leonard. A boke named Tectonicon. London: Iohn Daye, 1556.

DIGGES, Leonard. A booke named Tectonicon. London: Felix Kyngston, 1605 Disponível em:

https://ia802707.us.archive.org/17/items/bookenamedtecton00digg/bookenamedtecto $\% 2$ 0n00digg bw.pdf Acesso em: 01 jan. 2020.

MARCONI, Marina de Andrade; LAKATOS, Eva Maria. Fundamentos de Metodologia Científica. 5. ed. São Paulo: Atlas S.A, 2003. 311 p.

PAULINO, Sabrina de Sousa; ARGEMIRO FILHO, Carlos Ferreira; PEREIRA, Ana Carolina Costa. ALGUNS ASPECTOS CONTEXTUAIS DA RÉGUA 1E DO ESQUADRO DE CARPINTEIRO NO TRATADO A BOOKE NAMED TECTONICON (1556) DE LEONARD DIGGES. Boletim Cearense de Educação e História da Matemática, [S.L.], v. 7, n. 20, p. 170-180, 12 jul. 2020. Boletim Cearense de Educacao e Historia da Matematica - BOCEHM.

http://dx.doi.org/10.30938/bocehm.v7i20.2838.

PAULINO, Sabrina de Sousa; PEREIRA, Ana Carolina Costa. A abordagem de conceitos matemáticos por meio da tabela de medidas da madeira de Leonard Digges (1520-1559). Remat: Revista Eletrônica da Matemática, [S.L.], v. 7, n. 1, p. e2007, 6 abr. 2021. Instituto Federal de Educacao - Ciencia e Tecnologia do Rio Grande do Sul. http://dx.doi.org/10.35819/remat2021v7i1id4265.

PEREIRA, Ana Carolina Costa; BATISTA, Antonia Naiara de Sousa; SILVA, Isabelle Coelho da. A balestilha descrita na obra Chronographia repertorio dos tempos (1603): discussões iniciais sobre o saber incorporado no instrumento. Boletim Cearense de Educação e História da Matemática, Fortaleza, v. 11, n. 4, p.105-118, dez. 2017.

PEREIRA, Ana Carolina Costa; SAITO, Fumikazu. A reconstrução do báculo de Petrus Ramus na interface entre história e ensino de matemática. Revista Cocar, v. 13, n. 25 , pp. 342-372, 2019.

PEREIRA, Ana Carolina Costa; SAITO, Fumikazu. OS INSTRUMENTOS MATEMÁTICOS NA INTERFACE ENTRE HISTÓRIA E ENSINO DE 
MATEMÁTICA. Boletim Cearense de Educação e História da Matemática, [S.L.], v. 5, n. 14, p. 109-122, 25 ago. 2018. Boletim Cearense de Educacao e História da Matemática - BOCEHM. http://dx.doi.org/10.30938/bocehm.v5i14.225.

PRODANOV, Cleber Cristiano; FREITAS, Ernani César de. Metodologia do

Trabalho Científico: Métodos e Técnicas da Pesquisa e do Trabalho Acadêmico. 2. ed. Novo Hamburgo: Editora Feevale, 2013. 277 p. Disponível em:

$<$ https://www.feevale.br/institucional/editora-feevale/metodologia-do-trabalhocientifico---2-edicao>. Acesso em: 04 dez. 2020.

SÁ, Eliane Ferreira de et al. As aulas de graduação em uma universidade pública federal: planejamento, estratégias didáticas e engajamento dos estudantes. Revista

Brasileira de Educação, Rio de Janeiro, v. 22, n. 70, p. 625-650, jul. 2017. Disponível em:

$<$ https://www.scielo.br/scielo.php?pid=S1413-

$24782017000300625 \&$ script=sci_abstract\&tlng $=$ pt $>$. Acesso em: 03 dez. 2020.

SAITO, Fumikazu. A RECONSTRUÇÃO DE ANTIGOS INSTRUMENTOS MATEMÁTICOS DIRIGIDA PARA FORMAÇÃO DE PROFESSORES. Educação: Teoria e Prática, [S.L.], v. 29, n. 62, p. 571-589, 19 dez. 2019. Departamento de Educacao da Universidade Estadual Paulista - UNESP.

http://dx.doi.org/10.18675/1981-8106.vol29.n62.p571-589.

SAITO, Fumikazu. INSTRUMENTOS MATEMÁTICOS DOS SÉCULOS XVI E XVII NA ARTICULAÇÃO ENTRE HISTÓRIA, ENSINO E APRENDIZAGEM DE MATEMÁTICA. Revista de Matemática Ensino e Cultura, ano 9, n. 16, p. 25-47, maio-ago., 2014.

SAITO, Fumikazu. História da matemática e suas (re)construções contextuais. São Paulo: Ed. Livraria da Física/SBHMat, 2015. [ISBN: 978-85-7861-372-3]

SILVA, Isabelle Coelho da. Um estudo da incorporação de textos originais para a educação matemática: buscando critérios na articulação entre história e ensino. 2018. 92 f. Dissertação (Mestrado) - Curso de Mestrado em Ensino de Matemática, Instituto Federal de Educação, Ciência e Tecnologia do Ceará, Fortaleza.

Recebido em: 05 / 03 / 2021

Aprovado em: 16 / 04 / 2021 